\title{
Environmental implications of increasingly stringent sewage discharge standards in municipal wastewater treatment plants: case study of a cool area of China
}

\author{
Xiu-Heng Wang ${ }^{\text {a, }}{ }^{\text {, Xu Wang }}{ }^{\text {b, c, }{ }^{*}, 1}$, Gjalt Huppes ${ }^{\mathrm{d}}$, Reinout Heijungs ${ }^{\mathrm{d}}$, Nan-Qi Ren ${ }^{\text {a }}$ \\ a State Key Laboratory of Urban Water Resource and Environment, School of Municipal and Environmental Engineering, Harbin Institute of Technology, \\ Harbin 150090, China \\ ${ }^{\mathrm{b}}$ Research Center for Eco-Environmental Sciences (RCEES), Chinese Academy of Sciences (CAS), Beijing 100085, China \\ c State Key Joint Laboratory of Environment Simulation and Pollution Control, RCEES, CAS, Beijing 100085, China \\ ${ }^{\mathrm{d}}$ Institute of Environmental Sciences, Leiden University, P.O. Box 9518, RA Leiden, The Netherlands
}

\section{A R T I C L E I N F O}

\section{Article history:}

Received 4 May 2014

Received in revised form

4 January 2015

Accepted 2 February 2015

Available online 11 February 2015

\section{Keywords:}

Wastewater treatment

Discharge standard

Environmental impact

Life cycle assessment

Sustainability

\begin{abstract}
A B S T R A C T
For the protection of the aquatic environment and public health, China has implemented increasingly stringent sewage discharge standards for municipal wastewater treatment plants (WWTPs), but faces critical challenges in terms of additional environmental burdens. In this work, a life cycle assessment (LCA) approach was used to determine the adverse environmental consequences of increasingly stringent discharge standards in a domestic WWTP, and to identify the main contributors and propose alternatives that minimize negative environmental impacts. The LCA-derived findings indicate that tightening discharge levels will indeed reduce local eutrophication but without net environmental improvement satisfied. If the treated water is not required for further reuse, it appears more environmentally promising to establish WWTPs in regions that implementing moderate-level treatment than to upgrade existing WWTPs to much higher standards, except in conservation zones, areas of high population density, and in watersheds with less resilience to pollution. Overall, environmental improvement can be satisfied by introducing consistent "cradle-to-cradle/grave" legislation for WWTPs. It was implicated that decision makers should therefore emphasize energy conservation and wastewaterderived resource recovery approaches to the operation of WWTPs.
\end{abstract}

๑) 2015 Elsevier Ltd. All rights reserved.

\section{Introduction}

Legislation is continuously refining the needs for the removal of various pollutants from domestic sewage. To this end, the Ministry of Environmental Protection of the People's Republic of China (MEP) introduced the Discharge Standard of Pollutants for Municipal Wastewater Treatment Plants (MEP, 2002a), updated from the 1996 version. In China, surface waters are classified from level I (the cleanest, functioning as national conservation areas, etc.) to level $\mathrm{V}$, and those below $\mathrm{V}$ (lowest quality, not suitable for industrial or agricultural

\footnotetext{
* Corresponding author. Research Center for Eco-Environmental Sciences (RCEES), Chinese Academy of Sciences (CAS), Beijing 100085, China. Tel./fax: +8610 62923543.

E-mail addresses: xiuheng@hit.edu.cn (X.-H. Wang), xuwang@rcees.ac.cn (X. Wang).

${ }^{1}$ X.-H. Wang and X. Wang contributed equally to this work.
}

use), based on their natural characteristics and conservation objectives permitted by Surface Water Quality Standards (MEP, 2002b). The effluent standard implemented in domestic wastewater treatment plants (WWTPs) depends on the classification of the receiving water environment and the design age of the WWTP. Some of the WWTPs in China were constructed during 1990s primarily aimed at removal of organic substances according to the former standard, so-called Class 2. WWTPs constructed after 1998 have nutrient removal capacity that should further meet Class $1 \mathrm{~B}$, whereas some older WWTPs are required to be upgrading to qualify for Class $1 \mathrm{~B}$ as the receiving water is of level III (suitable for fishery and swimming).

A new, and more stringent effluent level, referred to as Class $1 \mathrm{~A}$, is needed as the effluent is to be reused or discharged to a recreational or scenic viewing water body that has less diluting capacity (MEP, $2002 \mathrm{~b})$. An amendment was also passed in 2006, stating that class $1 \mathrm{~A}$ must be enforced at places identified as national and provincial 'priority watersheds and lakes'. At the national scale alone, this 
designation accounts for $40 \%$ of the Chinese land area and $60 \%$ of its population. Implementation of the new level has led to the rapid upgrading of WWTPs across China. Of the 60 billion tons of sewage discharged in China in 2008, around $40 \%$ was treated, with a target of $60 \%$ for urban areas in the following years. The long-standing need for ecological sustainability raises the critical question that whether it is necessary to go beyond the protection of human health to include the local amenity of rivers in some special areas. This issue is especially relevant when even the simple goal of installing a WWTP, to ensure hygiene and drainage, is not being achieved in most rural or less developed areas, where no sewers exist in reality.

The new standard seems highly concise when described in the traditional manner, only focusing on specific water quality parameters. Upgrading WWTPs will give rise to other adverse environmental effects owning to energy and chemicals consumptions, waste activated sludge (WAS) production, and greenhouse gas emission, representing a clear example of problem-shifting. If WWTPs are designed and operated to solve local-scale environmental problems without taking into account the global nature of the environment, it is possible that no net environmental improvement will be gained. On this respect, all environmental consequences throughout the life cycle of a WWTP should be considered recommendable. Life cycle assessment (LCA) is considered as a 'cradle-to-grave' approach that estimates several potential environmental impacts of a product and/or a service from a whole life cycle perspective (Corominas et al., 2013). Some LCA studies concentrated on the sustainability of wastewater treatment systems (Fuchs et al., 2011; Lundie et al., 2004; Pasqualino et al., 2009); compared different treatment stages and alternative techniques, including advanced wastewater treatment and recycling (Foley et al., 2010a, 2010b; Wang et al., 2012a); or have taken the form of case studies (Zhang et al., 2010; Zhu et al., 2013).

In the present work, we used an LCA approach to estimate the operational stages of a representative WWTP locates in a cool area of China, using three alternative effluent-based scenarios according to increasingly stringent discharge standards permitted by Chinese discharge regulations for further estimates. Subsequently, the key contributors were identified with quantification of their adverse effects on the natural environment. Throughout the work, we focused on optimizing the level of sewage treatment, and investigating policy-driven transitions to less aggressive and environmentally harmful options.

\section{Methodology}

\subsection{Life Cycle Assessment (LCA) approach}

Negative environmental impacts were assessed with a general LCA approach, i.e., the CML 2002 developed by Leiden University (Guinee et al., 2002), resulting in a single score for each impact category. The CML 2002 LCA method aims to offer best practice for midpoint indicators, operationalizing the ISO 14040 series of standards. Specifically, the impact categories embraced were as follows: abiotic depletion of elements (ADE: kg antimony eq.), abiotic depletion of fossil fuels (ADF: MJ), global warming (GW: $\mathrm{kg} \mathrm{CO}_{2}$ eq.), ozone depletion (OD: kg CFC-11 eq.), human toxicity (HT: kg 1,4-DCB eq.), freshwater aquatic ecotoxicity (FAET: $\mathrm{kg}$ 1,4-DCB eq.), photochemical oxidation (PO: kg ethylene eq.), acidification (A, global: $\mathrm{kg} \mathrm{SO}_{2}$ eq.), and eutrophication (E: $\mathrm{kg} \mathrm{PO}_{4}$ eq.). According to the internationally standardized LCA framework (Guinee, 2002), the estimated scores of the impact categories for the three investigated scenarios were subsequently normalized using a previous approach (Sleeswijk et al., 2008). Since each impact category has relative significance, the weighting of all impact categories is also considered herein. However, the weighting element has always been a controversial issue owning to required incorporation of social, political, and ethical values (Schmidt and Sullivan, 2002). Moreover, there is no best weighting method available, and there is no recommended set of weighting factors for Chinese cases (Wang et al., 2012b). A weighting method covering the mid-point level recommended to the European Union was thus used (Huppes and van Oers, 2010), and the average values of three parallel sets of weighting factors were employed to determine the relative significance of the impact categories (Table S1).

\subsection{Scenario description}

A domestic WWTP, locating in a cool area of China, was selected as representative for further evaluations. The focused WWTP operates at a capacity of $1.0 \times 10^{4} \mathrm{~m}^{3} / \mathrm{d}$ using cyclic activated sludge technique, and assumed to meet the three increasingly stringent requirements permitted by Chinese discharge regulations (MEP, 2002a). The sewage characteristics and brief information of the proposed effluent-based scenarios (Scenario 2, Scenario $1 \mathrm{~B}$, and Scenario $1 \mathrm{~A}$ ) are presented in Table 1 and Table S2. It should be further noted that the evaluated WWTP was designed without primary sedimentation to maintain the necessary carbon to nitrogen ratio of denitrification following the most general trends. The WAS produced from biological processes is initially thickened, dewatered by a belt filter press, and subsequently assumed to be transported for off-plant landfill disposal. Additionally, the function unit of the study was the amount of sewage treated at the WWTP per day with the subsequent sludge treatment expressed in units of $10^{4} \mathrm{~m}^{3}$, presenting the sewage by $2.56 \times 10^{4}$ population equivalent $(\mathrm{PE}) / \mathrm{d}$.

\subsection{System boundaries}

Here, the system boundary was defined as the raw sewage arriving at the WWTP and included all emits (liquid phase, solid

Table 1

Part of the Chinese wastewater discharge standard and summary of the studied scenarios (mg/L).

\begin{tabular}{|c|c|c|c|c|c|c|c|}
\hline \multirow[t]{2}{*}{ Parameter } & \multicolumn{3}{|c|}{ Standard } & \multicolumn{4}{|c|}{ Influent and effluent quality of scenarios } \\
\hline & Class 2 & Class 1B & Class $1 \mathrm{~A}$ & Scenario $1 \mathrm{~A}$ & Scenario $1 \mathrm{~B}$ & Scenario 2 & Influent \\
\hline Chemical oxygen demand (COD) & 100 & 60 & 50 & 29.8 & 42.6 & 80 & 259.2 \\
\hline Biochemical oxygen demand $\left(\mathrm{BOD}_{5}\right)$ & 30 & 20 & 10 & - & 16.2 & - & 153.6 \\
\hline Suspended solids (SS) & 30 & 20 & 10 & 8.2 & 16.3 & 24 & 187.4 \\
\hline Total nitrogen $(\mathrm{TN})$ & - & 20 & 15 & 12.8 & 14.2 & 22.6 & 28.7 \\
\hline $\mathrm{NH}_{3}-\mathrm{N}$ & $25\left(30^{\mathrm{a}}\right)$ & $8\left(15^{\mathrm{a}}\right)$ & $5\left(8^{\mathrm{a}}\right)$ & - & 5.7 & - & 23.5 \\
\hline Total phosphorus (TP) & 3 & 1 & 0.5 & 0.5 & 0.8 & 2.2 & 3.4 \\
\hline \multirow[t]{4}{*}{ Facilities } & \multicolumn{3}{|c|}{ Primary treatment } & $\sqrt{ }$ & $\sqrt{ }$ & $\sqrt{ }$ & - \\
\hline & \multicolumn{3}{|c|}{ Secondary treatment } & $\sqrt{ }$ & $\sqrt{ }$ & $\sqrt{ }$ & - \\
\hline & \multicolumn{3}{|c|}{ Phosphorus removal } & $\sqrt{ }$ & $\sqrt{ }$ & - & - \\
\hline & \multicolumn{3}{|c|}{ Tertiary treatment } & $\sqrt{ }$ & - & - & - \\
\hline
\end{tabular}

$(\sqrt{ })$ present and equal; ( - indicates not present.

a Figures in parentheses are the standards when water temperature is lower than $12{ }^{\circ} \mathrm{C}$. 
phase and gas phase) to the local environments according to our pervious work (Wang et al., 2012a). Processes associated with the construction and demolition phase were ignored since they are generally negligible as compared with the operation phase (Lassaux et al., 2007; Lundin et al., 2000). Further, the WWTP was divided into five subsystems. It included not only the treatment of influent itself but also the inputs required, such as the production of electricity and the manufacture and transportation of chemicals, and the processing of WAS generated. The detailed configuration of the five subsystems is represented in the Supporting Information (Table S2). Hence, only the operational process was taken into account during the analysis.

\subsection{Data collection}

The present work was conducted with the cooperation and assistance of an environmental engineering firm, and also with site-specific data provided by their regular suppliers. Furthermore, supplementary data were mainly gained from Ecoinvent V2.2 databases (PRe-Product Ecology Consultants, 2012). Since no accurate data on electricity consumption were available per subsystem, electrical energy distribution across the whole process was determined using the rated power of the equipment comprising each unit, as well as the computed working hours (Wang et al., 2012b). The electric mix of China that applied for estimates embraces conventional thermal sources (81.5\%), hydroelectric sources (15.9\%), nuclear power (2.0\%), and other renewable energy like wind power $(0.6 \%)$, as represented in Ecoinvent V2.2. The European model was used herein as reference for transportation-related estimates. In addition, since most of the chemicals used in China are produced in Jiangsu Province, an average transportation distance of $2000 \mathrm{~km}$ was used for subsequent calculation, while the specific infrastructure for these processes and products was not taken into account. Furthermore, $\mathrm{N}_{2} \mathrm{O}$ emission from the anoxic tank was estimated to be around $0.68 \%$ of the denitrified nitrogen (Doka, 2003). $\mathrm{N}_{2} \mathrm{O}$ emission from the nitrogen-enriched river was also calculated according to a previous literature (McMahon and Dennehy, 1999). Additional key elements of the inventory data can be found in Table S3.

\section{Results and discussion}

\subsection{Options for local environmental improvement}

As presented in Table S4, the domestic WWTP was operated to satisfy effluent Class 2 (Scenario 2) and then being updated to a more stringent level of Class 1B (Scenario 1B) achieves greater environmental improvement in terms of eutrophication by enhanced removal of nitrogen and phosphorus from the effluent, compared with the situation that being directly optimized to meet Class $1 \mathrm{~A}$. The other environmental impacts are induced by the running of the WWTP, especially in terms of acidification, depletion of fossil fuels, freshwater ecotoxicity, and global warming. According to the subsequent weighted outcomes (Fig. 1), Scenario 1B is preferable to Scenario $1 \mathrm{~A}$ and Scenario 2, while the scores of Scenario $1 \mathrm{~A}$ worse than that of Scenario 2, indicating upgrading of WWTPs to a much stringent level offers no environmental gains. This is primarily due to increased freshwater ecotoxicity and global warming effects associated with the high electricity consumption in Scenario 1A. Ranking the three scenarios from a perspective of environmental benefit, we tend to recommend Scenario $1 \mathrm{~B}$ if the treated water is not to be reused or discharged to a conservation area. Our implication is quite consistent with previous literature (Lundie et al., 2004; Ng et al., 2014; Niero et al., 2014; Spangberg et al., 2014), which found that upgrading WWTP from primary to secondary was environmentally damaging unless there was a recycled resource in the offing.

Trade-offs between local- and global-scale environmental consequences would be addressed by both technical breakthroughs and policy developments. Specifically, technological innovation can improve economic and environmental performance of WWTPs and leads to varying evaluation outcomes. The present work only discusses the improvement alternatives that can be reached by policy development. Accordingly, local amenity can be further enhanced by substantial reduction in eutrophication. To this end, we conducted a detailed analysis of substances and sources that contribute to eutrophication (see Fig. 2). The emissions of nitrogen, phosphorus, and organic matter (in terms of COD) to water accounted for $\sim 86 \%$ of the overall impact in Scenario $1 \mathrm{~A}$, with $62 \%$ being contributed by nitrogen and $17 \%$ by phosphorus. Chinese statistics also show that the main pollution indicators of Chinese rivers are nitrogen and organic matter, while phosphorus is only identified as the main parameter for some lakes, not for rivers and reservoirs (MEP, 2009).

\subsection{Setting general legislation for watersheds}

As represented in Fig. 2, upgrading the studied WWTP from Class 1B (Scenario 1B) to Class 1A (Scenario 1A) reduces the eutrophication potential by $6.5 \%$ at the expense of a $29-40 \%$ increase in other environmental impacts, suggesting trade-offs occurred and no net environmental improvement gained. The reduced impact achieved through more compete removal of nutrients and organic pollutants is outweighed by the other induced impacts, mostly due to electricity for tertiary treatment and the consumption of chemicals. The current legislation implies that the cleaner the receiving river, the stricter the required discharge standard. Therefore, if the treated water is not reused but released into a clean river for public amenity, it is necessary to evaluate the standard in an environmentally holistic manner that incorporates inter-regional equity. For instance, a $40 \%$ increase in freshwater aquatic ecotoxicity potential may damage aquatic life in other rivers, because the toxic releases included in the LCA can take place in completely different watersheds.

In addition, an entirely clean river course cannot be achieved without considering the watershed as a whole. To this end, integrated management must account for the outwardly stringent but actually inconsistent discharge standards along the watershed. For instance, Class $1 \mathrm{~A}$ is applied to both the upstream and downstream stretches of the Songhua River of China, while Class 2 is implemented in the middle section of the river since the surface water there is presently of a lower quality. Although some 'priority watersheds and lakes' have been identified by the provincial authorities, watersheds do not coincide with overall political boundaries. If there is a WWTP in a tributary that operates at Class 2, upgrading this plant will reduce eutrophication by $\sim 5 \%$ only at the expense of increasing other impacts by $11-54 \%$ and $20 \%$ additional running costs for the WWTP. Another example is that of planning new WWTPs. The wastewater treatment rate in Heilongjiang Province, where the case study took place, was only $17 \%$ actually. According to the current legislation permitted in China, most newly constructed WWTPs should meet Class 1A. This would imply a further $6.5 \%$ reduction of the eutrophication, and with a $38 \%$ additional annuity for the WWTP compared to Class 1B.

\subsection{Establishing consistent legislation 'from cradle to cradle/grave'}

Global warming effects show negative outcomes ( $29 \%$ increase) by upgrading from Scenario $1 \mathrm{~B}$ to Scenario $1 \mathrm{~A}$. As shown in Fig. 3 , about $26 \%$ of $\mathrm{GW}$ is contributed by methane emission from 


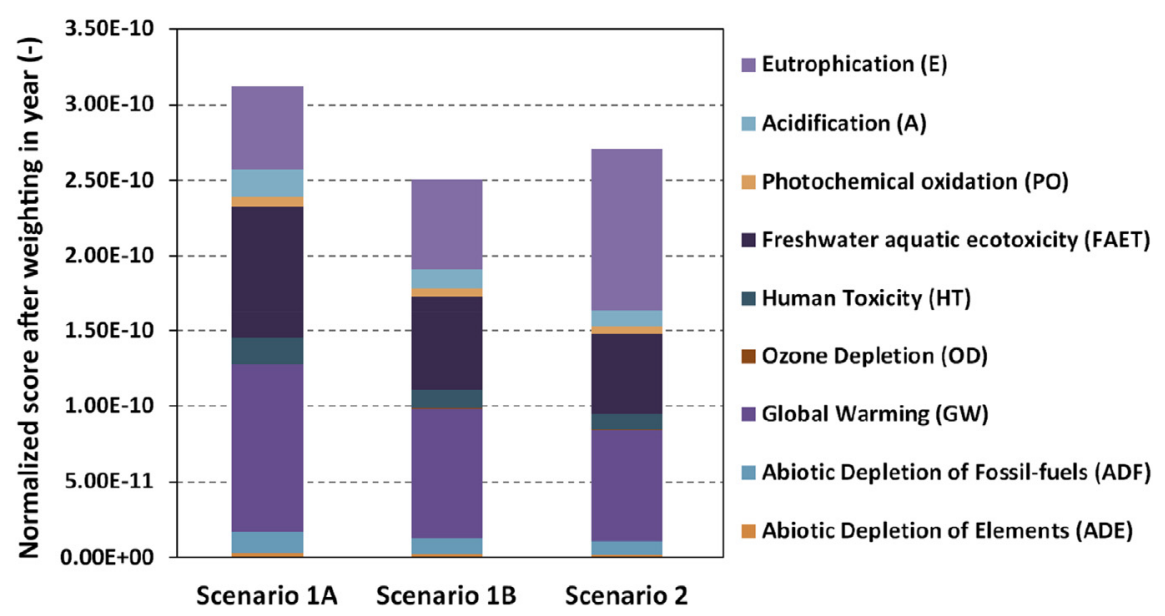

Fig. 1. Environmental impacts of different scenarios using a weighting set.

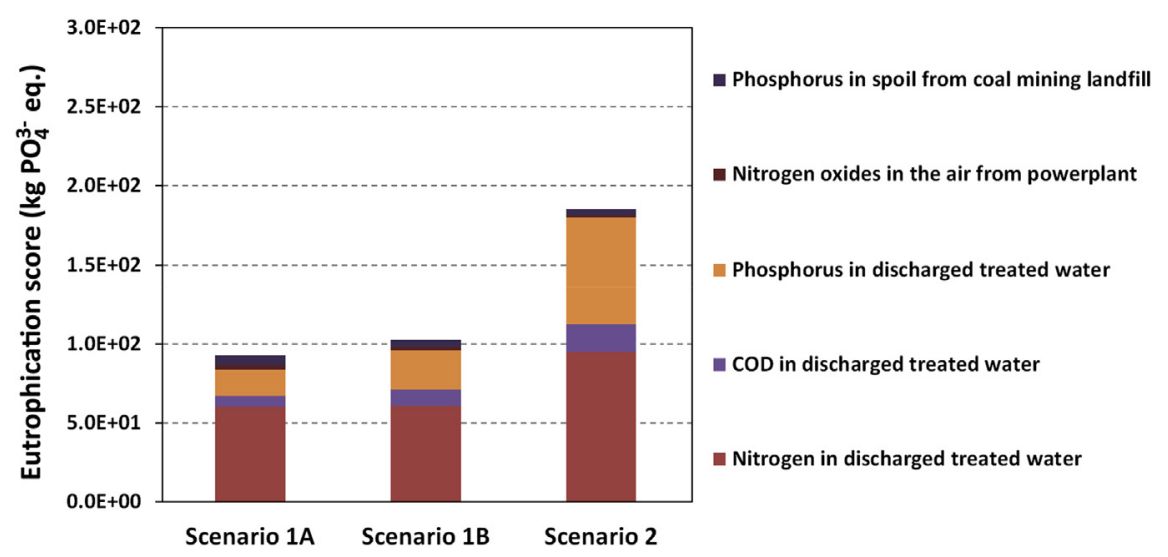

Fig. 2. Analysis of the contributions of the main substances involved in the eutrophication potential.

WAS landfill, and $35 \%$ by $\mathrm{CO}_{2}$ generation in electricity production. In our case, landfill gas is released directly into the atmosphere without collection involved, although the Standard for Pollution Control on the Landfill Site of Municipal Solid Waste recommends the introduction of effective measures to reduce methane generation and emissions, or the use of flare equipment (MEP, 2008). Due to operational costs and technical barriers, landfill gas in China is commonly released directly into the atmosphere without being collected and utilized (Han et al., 2009). Capturing and utilizing landfill gas will reduce the environmental risks involved in landfill management and also help mitigate the global warming potentials. Recovery efficiency of landfill gas depends on the operating conditions and the age of the wastes. Independent cases have yielded results ranging from $24 \%$ to $100 \%$ (Lou and Nair, 2009). Even if the landfill gas is collected at an average efficiency of only 35\% and then flared, the potentials of global warming can be reduced by $11 \%$ through the conversion of $\mathrm{CH}_{4}$ to $\mathrm{CO}_{2}$.

In addition, contribution analysis shows that acidification and fossil fuel depletion are associated with the use of fossil resources for electricity production. Electricity consumption is given as $\mathrm{kWh} /$ $\mathrm{PE} \cdot \mathrm{yr}$ rather than as a function unit, for comparison with other WWTPs. Stricter legislation would result in increased energy consumption, from $48.76 \mathrm{kWh} / \mathrm{PE} \cdot \mathrm{yr}$ (Scenario $1 \mathrm{~B}$ ) and $44.48 \mathrm{kWh} /$ $\mathrm{PE} \cdot \mathrm{yr}$ (Scenario 2) to $62.45 \mathrm{kWh} / \mathrm{PE} \cdot \mathrm{yr}$ (Scenario $1 \mathrm{~A}$ ). The electricity consumption for Scenario $1 \mathrm{~B}$ is much higher than those reported in the literature: $33 \mathrm{kWh} / \mathrm{kWh} / \mathrm{PE} \cdot \mathrm{yr}$ for a Swedish WWTP (service population: $7.2 \times 10^{4} \mathrm{PE}$ ) including chemical phosphorus removal but no nitrification (Lundin et al., 2000), and $28.6 \mathrm{kWh} / \mathrm{kWh} / \mathrm{PE} \cdot \mathrm{yr}$ for a WWTP (service population: $1.1 \times 10^{5} \mathrm{PE}$ ) without WAS digestion at a warmer area than in the present case (Hospido et al., 2008).

Our analysis of the options to reduce global warming, acidification, and fossil fuel depletion indicates that efforts to achieve energy savings and recovery are always problematic in numerous domestic WWTPs. In respect of technological innovation, efforts should concentrate on more efficient utilization of energy. Reducing electricity consumption by controlling air supply scheme (Baroni et al., 2006) or by employing high-efficiency air diffusers may become a practical strategy. Landfill gas could be utilized for energy generation (Ovezea, 2009). Using digester gas in WWTPs would be more environmentally beneficial than landfill gas capture (Bolzonella et al., 2006; Hospido et al., 2005; Wang et al., 2012b). Anaerobic digestion of WAS is not popular in China, which only has around ten such facilities. In addition, the energy gained from WAS digestion only represents around 30\% of the energy used by the WWTP, compared with 50\% in the United States (Wang, 2009). Small WWTPs and even the largest one (capacity $3.2 \times 10^{5} \mathrm{~m}^{3} / \mathrm{d}$ ) in Heilongjiang Province operate without WAS digestion. This is due to several practical factors, such as low winter temperatures, a lack of professional human operators, high investment requirements, and the present policy framework. 


\section{Biosolid landfill \\ Coal mining \\ - Coal burned in power-plant \\ Biotreatment process}

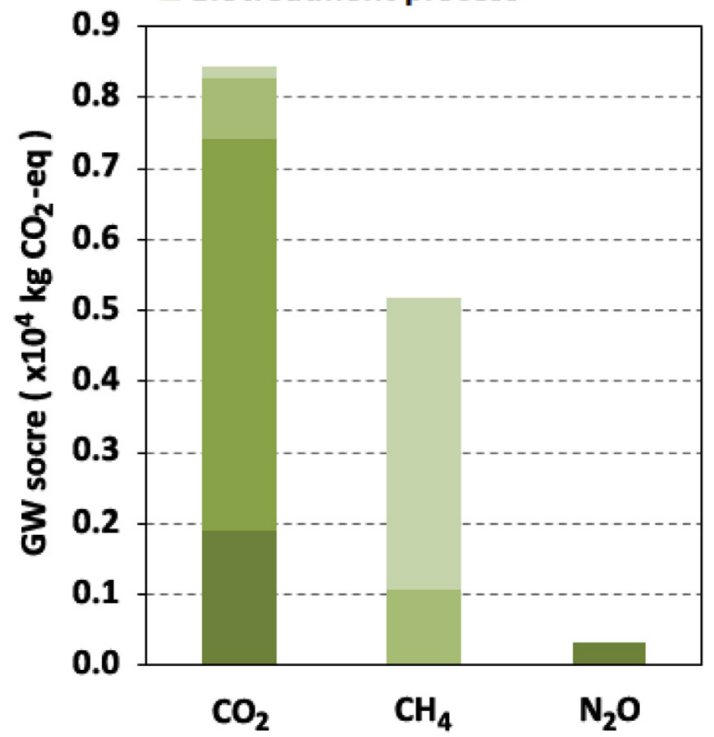

Fig. 3. Contribution analysis of the main substances and sources involved in GW potential in Scenario 1A.

However, sludge management cannot be overlooked while planning a WWTP. A study from Beijing reported that sludge disposal (drying, transport and landfill) cost 500 to 760 Yuan/t of dry sludge, which accounted for $15 \%$ of the WWTP operating costs (Zhang et al., 2006). In addition, the advantages of the co-digestion of WAS with bio-wastes are also well known and are due mainly to the increased methane yield and improved process stability, which is an additional alternative to facilitate augmenting energy capture from WAS (Dereli et al., 2010; Krupp et al., 2005; Righi et al., 2013). Rather than anaerobic digestion, the common means of sludge disposal in China is dewatering followed by landfill. According to a previous literature, landfill represents a worse sewage sludge treatment and end-use scenario than anaerobic digestion or reuse for fertilizer and cement manufacture (Murray et al., 2008). In Scenario $1 \mathrm{~A}$, sludge contributes $28 \%$ to global warming potential, $21 \%$ to photochemical oxidant formation, and $2-6 \%$ to other aspects when calculated on the basis of appropriate management. Statistics show that at least $13.7 \%$ of WAS in China is dumped arbitrarily, resulting in even greater environmental harm. If WAS is dumped in a river or along a river bank, leachate will cause a 5-9\% increase in eutrophication and a $2-4 \%$ increase in ecotoxicity. Similar effects are caused by leachate recirculation followed by direct discharge into water courses, which occurs in China despite being prohibited by regulations. In short, WAS not only exerts stress on the overall environment but also affects local amenity.

Recently, the Chinese Government has set limits that WAS tipping must not exceed $8 \%$ of the daily capacity of a landfill (MOHURD, 2007). The water content should be less than $60 \%$, since sludge with $80 \%$ water will cause cover layer sink in landfills. Lowering the water content implies lime stabilization or utilizing a higher proportion of coagulant. At the same time, the option of recycling sludge as fertilizer for agricultural soils is also questioned by farmers, in view of the heavy metals that may be introduced from industrial wastewater, which makes up about $17 \%$ of Chinese sludge (MOHURD, 2007). According to a previous literature (Chen et al., 2003), the average concentrations of trace elements in WAS in China were below the national standard (MEP, 2002a), but some samples showed values three times the standard for $\mathrm{Cd}, \mathrm{Cu}, \mathrm{Ni}, \mathrm{Pb}$, and $\mathrm{Zn}$. Since there is thus little opportunity to WAS disposal, it has become a major problem. Incineration, which reduces the volume of sludge to $30 \%$ of the initial solids content, also raises debate regarding the environmental benefits of energy production in comparison to the critical environmental and economic issues. Some documents indicated that including a cement kiln in the incineration system as a means of energy recovery considerably improved environmental performance from an LCA viewpoint (Peters and Rowley, 2009). Here again, we should mention anaerobic digestion as a means to minimize the amount of sludge and reap recoverable energy.

To this end, realistic regulatory policies on sludge management play a important role in determining the sustainability of WWTPs. Cost-effective approaches include minimizing sludge, introducing innovative sludge treatment technology, and treating sludge as a resource rather than waste. Meanwhile, policies should include enforcing source measures, reducing wastewater pollution atsource through altering critical production processes, the effective control of heavy metals and hazardous organic substances by pretreating industrial wastewater before discharge to municipal sewers, and therefore ensuring that sludge and effluent remain safe for agricultural application. This requires consistent legislation 'from cradle to grave', i.e., from source industrial wastewater to sludge, to be established for wastewater treatment.

\section{Implications of the work}

The present work evaluated discharge legislation on municipal WWTPs by means of a LCA-based case study in northern China. The LCA approach was applied to support decision making in wastewater treatment, combining site-specific problems with the global nature of the environment. The findings show that raising wastewater discharge standards from Class $1 \mathrm{~B}$ to Class $1 \mathrm{~A}$ will somewhat reduce eutrophication potential, especially locally, but will achieve no environmental improvement. From this overall perspective, therefore, more stringent discharge standards do not represent an environmentally cost-effective measure, because local amenity is already included in the overall judgment. This LCA study focuses on WWTPs in a climatically cool and less industrialized area, but particularly local-scale, and the characteristics of influent all significantly affect the relative merits of setting appropriate standards. Evaluating such increasingly stringent standards through an environmentally holistic approach including inter-regional equity, for instance by accounting for toxic releases in other watersheds, favors the establishment of new WWTPs in untreated regions rather than upgrading existing facilities. This seems preferable except for very specific areas such as national conservation zones or areas where water is reused, together with areas with high population density, and in watersheds with less resilience to pollution.

To enhance the local amenity, nitrogen elimination should be prioritized over phosphorus removal in the design of WWTPs, in order to reduce eutrophication risks. However, environmental improvement requires consistent legislation for wastewater treatment industry, with a viewpoint of 'from cradle to cradle/grave'. The policy framework should also include control of industrial wastewater discharge at source, facilitation of energy conservation in WWTPs, exploring sludge reduction strategies, and development updated scheme to combined wastewater treatment with resource recovery (water, energy, and materials).

In the present work, LCA approach is successfully used to estimate the environmental consequences of WWTP associated with increasingly stringent effluent standards. However, the uncertainty 
induced by assumptions in weighting element may be introduced in the estimation results, since environmental impact categories may have different significance in China, and the evaluation results may be affected by setting different weighting factors. Further efforts thus should be devoted toward proposing a favorable weighting approach for Chinese situations, and identifying the preferred weighting factors for all impact categories and providing a more powerful LCA-based tool for decision-makers. On the other hand, LCA is a more site-generic approach and its capability to address the ecotoxicological consequences of effluent on natural environment is still needed to be improved. Considering that LCA is a very time- and effort-intensive process, it is not surprising that previous literature including the present work on wastewater and/ or sludge treatment processes have only solved small components of a comprehensive LCA. To this end, if there are further concerns on the determinations of a certain impact category, such as ecotoxicity caused by sewage discharges, a combination of a sitespecific approach, such as eco-environmental risk assessment, and LCA may be desirable.

\section{Acknowledgments}

We are grateful to the National Natural Science Foundation of China (No. 51408589) and the State Key Joint Laboratory of Environment Simulation and Pollution Control of China (No. 14Z03ESPCR) for support.

\section{Appendix A. Supplementary data}

Supplementary data related to this article can be found at http:// dx.doi.org/10.1016/j.jclepro.2015.02.007.

\section{References}

Baroni, P., Bertanza, G., Collivignarelli, C., Zambarda, V., 2006. Process improvement and energy saving in a full scale wastewater treatment plant: air supply regulation by a fuzzy logic system. Environ. Technol. 27, 733-746.

Bolzonella, D., Battistoni, P., Susini, C., Cecchi, F., 2006. Anaerobic codigestion of waste activated sludge and OFMSW: the experiences of Viareggio and Treviso plants (Italy). Water Sci. Technol. 53, 203-211.

Chen, T.B., Huang, Q.F., Gao, D., Zheng, Y.Q., Wu, J.F., 2003. Heavy metal concentrations and their decreasing trends in sewage sludges of China. Acta Sci. Circumstantiae 23, 561-569.

Corominas, L., Foley, J., Guest, J.S., Hospido, A., Larsen, H.F., Morera, S., Shaw, A. 2013. Life cycle assessment applied to wastewater treatment: state of the art. Water Res. 47, 5480-5492.

Dereli, R.K., Ersahin, M.E., Gomec, C.Y., Ozturk, I., Ozdemir, O., 2010. Co-digestion of the organic fraction of municipal solid waste with primary sludge at a municipal wastewater treatment plant in Turkey. Waste Manage. Res. 28, 404-410.

Doka, G 2003 Life Cycle Inventories of Waste Treatment Services (Ecoinvent Report No. 13), Life Cycle Inventory of Wastewater Treatment. Swiss Centre for Life Inventories, Dubendorf.

Foley, J., de Haas, D., Hartley, K., Lant, P., 2010a. Comprehensive life cycle inventories of alternative wastewater treatment systems. Water Res. 44, 1654-1666.

Foley, J.M., Rozendal, R.A., Hertle, C.K., Lant, P.A., Rabaey, K., 2010b. Life cycle assessment of high-rate anaerobic treatment, microbial fuel cells, and microbial electrolysis cells. Environ. Sci. Technol. 44, 3629-3637.

Fuchs, V.J., Mihelcic, J.R., Gierke, J.S., 2011. Life cycle assessment of vertical and horizontal flow constructed wetlands for wastewater treatment considering nitrogen and carbon greenhouse gas emissions. Water Res. 45, 2073-2081.

Guinee, J.B., 2002. Handbook on Life Cycle Assessment: Operational Guide to the ISO Standards. Springer.

L., v.O., A., W.S., S., S., H.A., U.d.H., H., d.B., R., v.D., M.A.J., H. Guinee, J.B., Gorree, M., Heijungs, R., Huppes, G., Kleijn, R., 2002. Life Cycle Assessment: an Operationa Guide to the ISO Standards. Kluwer Academic Publishers, Dordrecht.

Han, H.B., Qian, G.R., Long, J.S., Li, S.D., 2009. Comparision of two different ways of landfill gas utilization through greenhouse gas emission reductions analysis and financial analysis. Waste Manage. Res. 27, 922-927.

Hospido, A., Moreira, M.T., Feijoo, G., 2008. A comparison of municipal wastewater treatment plants for big centres of population in Galicia (Spain). Int. J. Life Cycle Ass. 13, 57-64.
Hospido, A., Moreira, M.T., Martin, M., Rigola, M., Feijoo, G., 2005. Environmental evaluation of different treatment processes for sludge from urban wastewater treatments: anaerobic digestion versus thermal processes. Int. J. Life Cycle Ass. $10,336-345$.

Huppes, G., van Oers, L., 2010. Recommended Weighting Method for Measuring the EU-27 Overall Environmental Impact. CML, Leiden.

Krupp, M., Schubert, J., Widmann, R., 2005. Feasibility study for co-digestion of sewage sludge with OFMSW on two wastewater treatment plants in Germany. Waste Manage 25, 393-399.

Lassaux, S., Renzoni, R., Germain, A., 2007. Life cycle assessment of water from the pumpting station to the wastewater treatment plant. Int. J. Life Cycle Ass. 12, $118-126$.

Lou, X.F., Nair, J., 2009. The impact of landfilling and composting on greenhouse gas emissions - a review. Bioresour. Technol. 100, 3792-3798.

Lundie, S., Peters, G.M., Beavis, P.C., 2004. Life cycle assessment for sustainable metropolitan water systems planning. Environ. Sci. Technol. 38, 3465-3473.

Lundin, M., Bengtsson, M., Molander, S., 2000. Life cycle assessment of wastewater systems: Influence of system boundaries and scale on calculated environmental loads. Environ. Sci. Technol. 34, 180-186.

McMahon, P.B., Dennehy, K.F., 1999. N20 emissions from a nitrogen-enriched river. Environ. Sci. Technol. 33, 21-25.

MEP, 2002a. Discharge Standard of Pollutants for Municipal Wastewater Treatment Plant (GB18918-2002). China Environment Press, Beijing.

MEP, 2002b. Surface Water Quantity Standards (GB8938-2002). China Environment Press, Beijing.

MEP, 2008. Standard for Pollution Control on the Landfill Site of Municipal Solid Waste. China Environment Press, Beijing.

MEP, 2009. China Environmental Statistics Yearbook 2008. China Environment Press, Beijing.

MOHURD, 2007. The Disposal of Sludge from Municipal Wastewater Treatment Plant - Sludge Quality for Co-landfilling (CJ/T249-2007). China Standard Press, Beijing.

Murray, A., Horvath, A., Nelson, K.L., 2008. Hybrid life-cycle environmental and cost inventory of sewage sludge treatment and end-use scenarios: a case study from China. Environ. Sci. Technol. 42, 3163-3169.

Ng, B.J.H., Zhou, J., Giannis, A., Chang, V.W.C., Wang, J.Y., 2014. Environmental life cycle assessment of different domestic wastewater streams: policy effectiveness in a tropical urban environment. J. Environ. Manage 140, 60-68.

Niero, M., Pizzol, M., Bruun, H.G., Thomsen, M., 2014. Comparative life cycle assessment of wastewater treatment in Denmark including sensitivity and uncertainty analysis. J. Clean. Prod. 68, 25-35.

Ovezea, A., 2009. Saving energy: using fine bubble diffusers. Filtr. Sep. 46, 24-27.

Pasqualino, J.C., Meneses, M., Abella, M., Castells, F., 2009. LCA as a decision support tool for the environmental improvement of the operation of a municipal wastewater treatment plant. Environ. Sci. Technol. 43, 3300-3307.

Peters, G.M., Rowley, H.V., 2009. Environmental comparison of biosolids management systems using life cycle assessment. Environ. Sci. Technol. 43, 2674-2679.

Righi, S., Oliviero, L., Pedrini, M., Buscaroli, A., Della Casa, C., 2013. Life cycle assessment of management systems for sewage sludge and food waste: centralized and decentralized approaches. J. Clean. Prod. 44, 8-17.

Schmidt, W.P., Sullivan, J., 2002. Weighting in life cycle assessments in a global context. Int. J. Life Cycle Ass. 7, 5-10.

Sleeswijk, A.W., van Oers, L., Guinee, J.B., Struijs, J., Huijbregts, M.A.J., 2008. Normalisation in product life cycle assessment: an LCA of the global and European economic systems in the year 2000. Sci. Total Environ. 390, 227-240.

Spangberg, J., Tidaker, P., Jonsson, H., 2014. Environmental impact of recycling nutrients in human excreta to agriculture compared with enhanced wastewater treatment. Sci. Total Environ. 493, 209-219.

Wang, K.J., 2009. To provide technical policy guidance sludge disposal: Interpretation of policy and technologies of pollution prevention and control for treatment and disposal of sludge from municipal wastewater treatment plant (on trial). Constr. Sci. Technol. 52-53.

Wang, X., Liu, J.X., Ren, N.Q., Duan, Z.S., 2012a. Environmental profile of typical anaerobic/anoxic/oxic wastewater treatment systems meeting increasingly stringent treatment standards from a life cycle perspective. Bioresour. Technol. $126,31-40$.

Wang, X., Liu, J.X., Ren, N.Q., Yu, H.Q., Lee, D.J., Guo, X.S., 2012b. Assessment of multiple sustainability demands for wastewater treatment alternatives: a refined evaluation scheme and case study. Environ. Sci. Technol. 46, 5542-5549.

Zhang, Q.H., Wang, X.C., Xiong, J.Q., Chen, R., Cao, B., 2010. Application of life cycle assessment for an evaluation of wastewater treatment and reuse project - case study of Xi'an, China. Bioresour. Technol. 101, 1421-1425.

Zhang, Y.A., Gao, D., Chen, T.B., Zheng, G.D., Li, Y.X., 2006. Economical evaluation of different techniques to treatment and dispose sewage sludge in Beijing. Ecol. Environ. 15, 234-238.

Zhu, L., Liu, B., Wang, F., Bi, J., 2013. Raising discharge standards leads to environmental problem shifting in China. Water Sci. Technol. 68, 2605-2612. 